\title{
From Alkaline Earth Ion Aggregates via Transition Metal Coordination Polymer Networks towards Heterometallic Single Source Precursors for Oxidic Materials
}

\author{
Fabienne Gschwind, Aurélien Crochet, William Maudez, and Katharina M. Fromm
}

\begin{abstract}
Heterometallic oxides are used as materials in many applications, e.g. from ferroelectrics to superconductors. Making these compounds usually requires high temperatures and long reaction times. Molecular precursors may contribute to render their processing shorter and accessible at lower temperatures, thus cheaper in energy and time. In this review article, different approaches toward oxide materials will be shown, starting with homometallic clusters and coordination polymers and highlighting recent results with heterometallic single source precursors. On the way to the latter, we came across many exciting results which themselves allowed applications in different fields. This work will give an overview on how these fields were brought together for the current mixed metallic compounds as precursors for heterometallic oxides.
\end{abstract}

Keywords: Cluster compounds · Coordination polymers · Metal organic frameworks · Oxide materials · Single source precursors

\section{Introduction}

The generation of oxide materials is an important task for Society: it includes the search for high temperature superconductors for resistance-less and thus loss-free electronic conduction ${ }^{11]}$ or the development of new ceramics able to resist high temperatures ${ }^{[2]}$ e.g. for the design of ultra high-speed spaceships and airplanes - an issue in long-distance transportation - to name a few current trends of applications.

Oxide materials can be made by various well established procedures. ${ }^{[3]}$ Yet the most used one is a solid-state chemical approach which consists of heating a mixture of homometallic pure oxides or carbonates to very high temperatures over long reaction times, and to anneal the final mixed metal compound in oxygen or under vacuum in order to achieve the final properties. Such processing is expensive both in terms

\footnotetext{
${ }^{\star}$ Correspondence: Prof. Dr. K. M. Fromm University of Fribourg

Department of Chemistry

Chemin du Musée 9

$\mathrm{CH}-1700$ Fribourg

Tel.: + 41263008732

Fax: + 41263009738

E-mail: katharina.fromm@unifr.ch
}

of energy and time. Other approaches have therefore been developed, such as sol-gel techniques, ${ }^{[4]}$ spray- or dip-coating, ${ }^{[5]}$ as well as metal-organic chemical vapor deposition (MO-CVD) in order to make thin films of the desired oxides. ${ }^{6]}$ Generally, a mixture of volatile metal compounds is used to generate the target oxides. Yet, for alkaline earth metal diketonates ${ }^{[7]}$ or ketoimines, ${ }^{[8]}$ oligomerisation, as well as insufficient volatility and stability are often a problem.

\section{Results and Discussion}

For many years, it has been our goal to contribute to this exciting field of research and to design new molecular precursors for the generation of oxide materials.

\section{s-Block Compounds}

To start with, we focused on the group 1 and 2 metal compounds ${ }^{[9-35]}$ because many of these are problematic in techniques like MO-CVD or sol-gel due to their hydrophilicity and their tendency to decompose or oligomerize prior to deposition of the desired material. This has first led us to the field of alkali ${ }^{[9-12]}$ and alkaline earth metal compounds, ${ }^{[13,14]}$ of which a number of new clusters were observed. ${ }^{[15-23]}$ Being hard metal ions, mainly O-donor ligands were chosen for the coordination to these group 1 and 2 ions. Among these ligands are charged monodentate ligands $\mathrm{OR}, \mathrm{R}=\mathrm{H}$, alkyl, aryl, ${ }^{[22,23]}$ as well as the neutral polyether ligands such as oligo di- methyl ethers, ${ }^{[24-32]}$ crown ethers ${ }^{[33,34]}$ or calixarene ligands..$^{[9-12]}$ While studying these compounds, some of them exhibited unforeseen structures and properties, such as the ion-conductivity observed in one-dimensionally stacked crown ethers or calixarenes.[10,34] Especially the mixed metal cage compounds containing alkali and alkaline earth metal ions, like the $\left[\mathrm{CaLi}_{6}(\mathrm{OPh})_{8}(\text { thf })_{6}\right]$ of Fig. 1, are interesting also for catalysis of e.g. polystyrene synthesis.[22 and refs therein]

The monometallic polyether adducts of alkaline earth metal halides possess structures in which the O-donor ligand wraps around the cation (Fig. 1, left). Unfortunately, they often turned out to form mainly carbonates at low decomposition temperatures, while some of the cluster compounds (Fig. 1, right) were shown to be successful candidates as starting compounds for the sol-gel as well as MO-CVD method to yield alkaline earth oxides, ${ }^{[18]}$ and are still studied in our group.

\section{Transition Metal Coordination Compounds and Polymers}

Among the polyether adducts, we have recently extended our research into the field of transition metal compounds. ${ }^{[35]}$ We are currently studying these complexes with respect to their potential as starting materials for new cluster compounds, e.g. with magnetic properties. In some of these compounds, polyethers can act as bridging ligands between metal ions in order to yield one-dimensional coordination polymers (Fig. 2). These compounds are how- 


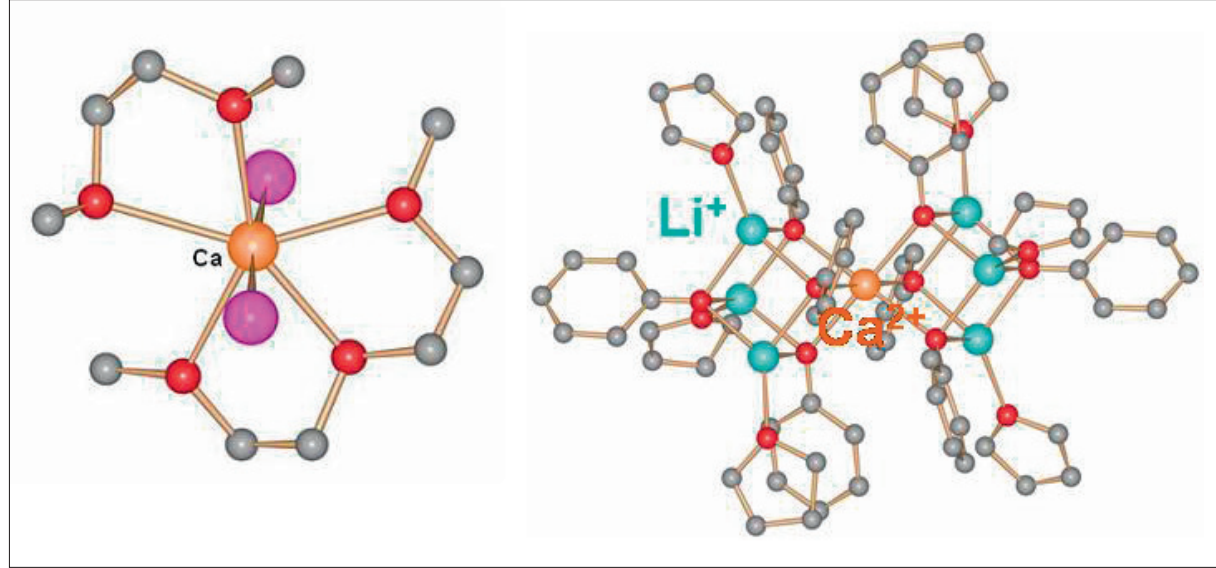

Fig. 1. [ $\mathrm{Cal}_{2}(\mathrm{dme})$ (diglyme)] (left) and $\left[\mathrm{CaLi}_{6}(\mathrm{OPh})_{8}(\mathrm{thf})_{6}\right]$ (adapted from ref. [22]) (right) (H-atoms omitted for clarity; Ca: orange, Li: light blue, O: red; C: grey, I: violet).

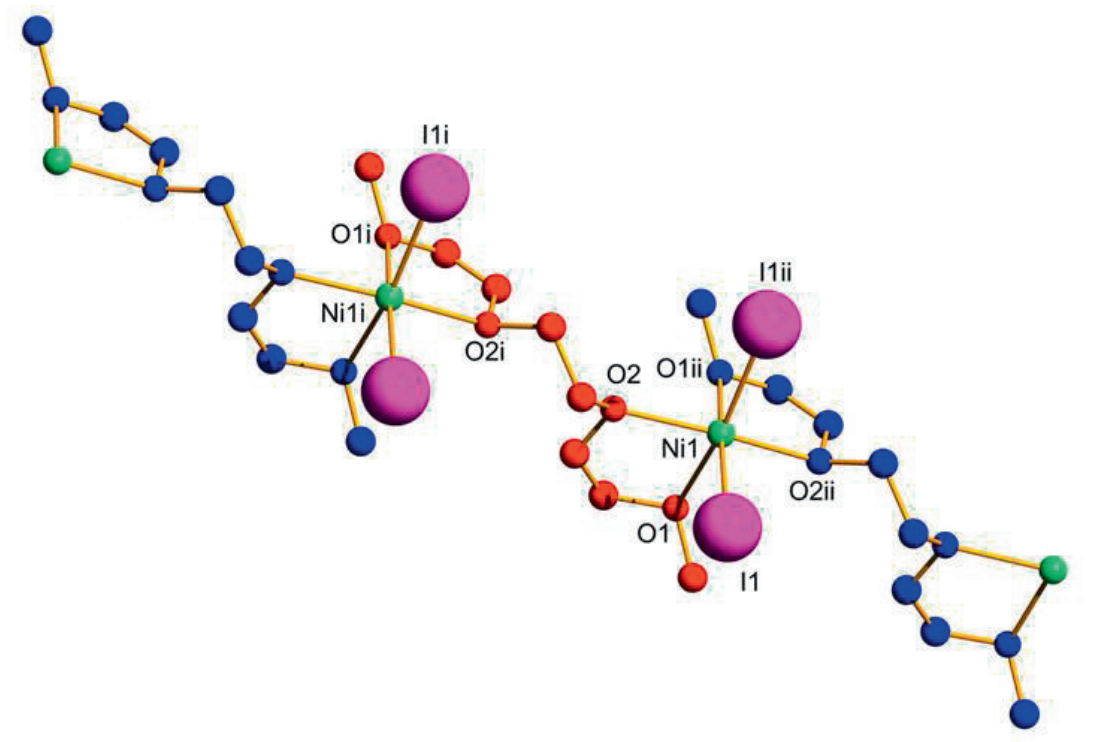

Fig. 2. A one-dimensional coordination polymer obtained from $\mathrm{Nil}_{2}$ and triglyme (adapted from ref [35]; triglyme ligands shown in red and blue, Ni: green, I: pink; H-atoms omitted for clarity).

ever very sensitive to e.g. humidity and therefore not easy to handle when it comes to the generation of oxide materials.

Therefore, we decided to design ligands in such a way as to be able to coordinate two different metal ion types by one such ligand in order to form stable single-source precursors. ${ }^{[36,37]}$ Furthermore, the ligand has to be easily synthesized and available in large quantities at a low cost, because it

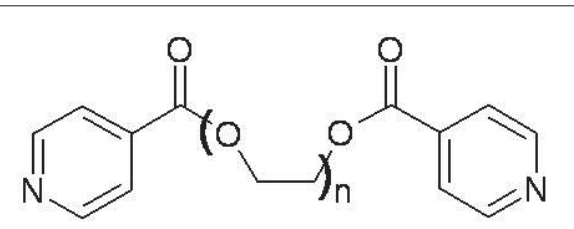

Fig. 3. Ligand series $\operatorname{Ln}(n=1,2,3,4)$ used for homometallic coordination polymer generation and heterometallic single source precursors. rently in development as coatings for implant materials. ${ }^{[44-47]}$

With the longer ligand L2, mainly metallacycles based on two silver ions and two ligands are observed, with the exception of a one-dimensional simple helical compound (Fig. 4) ${ }^{[48]}$ and a two-dimensional polycatenated structure. ${ }^{[49,50]}$

\section{Heterometallic Compounds}

Given the coordination mode of polyethers versus alkaline earth metal ions and the way that our ligand series Ln coordinated to transition metal ions, it could be predicted that a ligand with a longer polyethylene chain like L4 would be able to bind two different metal ions as shown in Scheme 1 (top). Indeed, it was recently shown that the ligand L4 binds selectively with the $\mathrm{O}$-atoms to calcium in order to yield monometallic complexes.[36] If only $\mathrm{Cu}(\mathrm{I})$ ions are present in solution, ligand L4 binds to copper ions only via the N-atoms to form a porous metal-organic framework (MOF) based on $\mathrm{Cu}_{4} \mathrm{I}_{4}$-nodes and the connecting ligands. This MOF was shown to be highly porous and to take up reversibly gases like nitrogen. Furthermore, this compound presents different luminescent properties as a function of the solvent from which it is isolated. [36]

The next step was thus to bring both metal ions together and to form a heterometallic compound. We could show that this process requires a step-wise synthesis, but which can be carried out in one pot:

i) in a first reaction, the ligand L4 is exposed to calcium ions. The ligand, which is flexible, will wrap around the metal cation and will be preorganized in this way (Scheme 1).

ii) in a second step, the $\mathrm{CuI}$ is added into the reaction mixture. The ligand L4 is now able to bind to copper ions in the expected fashion to form a heterometallic compound. The copper ions form $\mathrm{a} \mathrm{Cu}_{3}$-cluster unit bridged by iodide ions to yield a $\mathrm{Cu}_{3} \mathrm{I}_{4}^{-}$unit. One iodide I1 (Scheme 1) connects then to the next neighbor copper ions, by which a one-dimensional $\mathrm{Cu}$-I-polymer is obtained. The calcium complexes are 'attached' to the polymer chain in a syndiotactic fashion.

\section{Thermal Decomposition \\ Experiments and Oxide Formation}

The homometallic complexes of calcium obtained with $\mathrm{L} 4$, namely $\left[\mathrm{Ca}(\mathrm{L} 4)\left(\mathrm{H}_{2} \mathrm{O}\right)_{3}\right]$ $\mathrm{I}_{2}$ and an isomer of this compound, turned out to yield $\mathrm{CaCO}_{3}$ upon thermal decomposition. The compound $\left\{\left[\mathrm{CaI}\left(\mathrm{H}_{2} \mathrm{O}\right)_{2}(\mathrm{~L} 4)\right]\right.$ $\left.\left[\mathrm{Cu}_{3} \mathrm{I}_{4}\right]\right\}_{n}$ contains a $\mathrm{Ca}: \mathrm{Cu}$ ratio of $1: 3$. Its TGA analysis in air showed a onestep decomposition process around 290 ${ }^{\circ} \mathrm{C}$, associated with a total weight loss of $84.4 \%$, which corresponds to the loss of ligand and five iodide ions (82.4\%). nation compounds were shown to possess good antimicrobial properties and are cur- ion $\mathrm{Cu}^{+}, \mathrm{Cu}^{2+} \mathrm{L} 1$ and the group 11 metal polymers were obtained. ${ }^{[38-43]}$ ligand, independently of the length, L1 or L2, always binds to the transition metal compounds via the nitrogen donor atom only. The one-dimensional silver coordi- 


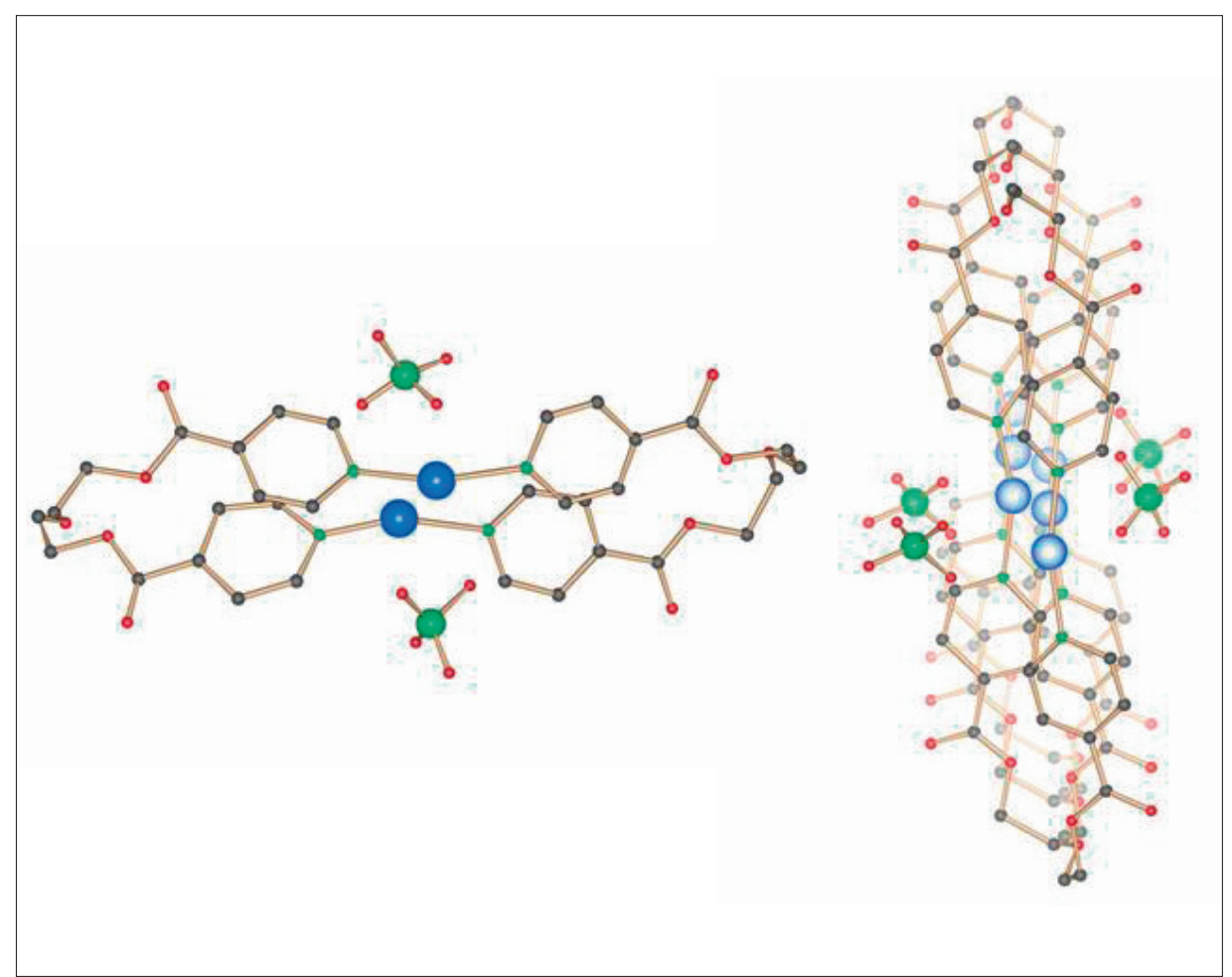

Fig. 4. Two polymorphs of $\left[\mathrm{Ag}(\mathrm{L2} 2) \mathrm{ClO}_{4}\right]_{x}, x=2$ (left), $\times=\infty$ (right) [47] (Ag: blue, N: green, O: red; C: grey; $\mathrm{H}$-atoms omitted for clarity).

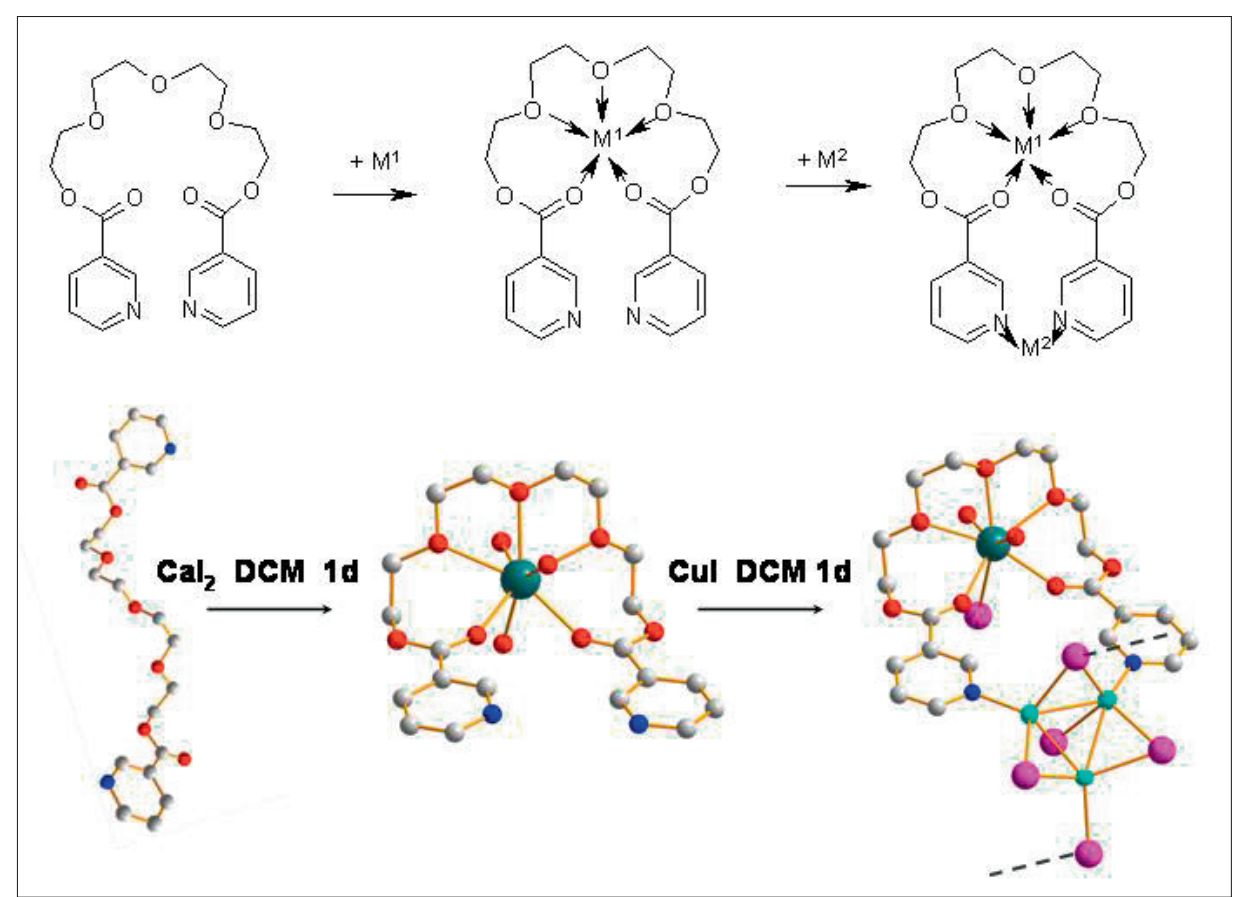

Scheme 1. Ligand L4 and its successive coordination of two different metal ions, M1 and M2 $(\mathrm{M} 1=\mathrm{Ca}, \mathrm{M} 2=\mathrm{Cu}(\mathrm{I}))(\mathrm{Ca}$ : green-grey, $\mathrm{Cu}$ : blue, O: red, N: dark blue, C: grey, I: violet; grey dotted lines indicate bridging of iodide to the next $\mathrm{Cu}_{3}$-cluster).

Heating of $\left\{\left[\mathrm{CaI}\left(\mathrm{H}_{2} \mathrm{O}\right)_{2}(\mathrm{~L} 4)\right]\left[\mathrm{Cu}_{3} \mathrm{I}_{4}\right]\right\}_{n}$ in air to $>290{ }^{\circ} \mathrm{C}$ yields a black powder, for which we could propose a new mixed metal oxide composition $\mathrm{CaCu}_{2.8} \mathrm{O}_{x} \cdot{ }^{[36]}$ Since then, we have also been able to isolate heterometallic compounds containing barium and copper(I) ions in different ratios, which, upon thermal decomposition, ent metal ion types at their individual donor sites. Their selective binding behavior was shown for alkaline earth metal ions on one hand and group 11 transition metal ions on the other. New heterometallic compounds were characterized and shown to yield mixed metal oxides. Large-scale syntheses of ligand and complexes are available. One of our current research areas continues to cover our efforts to include a third metal ion in order to generate superconducting oxides.

\section{Acknowledgements}

The authors thank the Swiss National Science Foundation, the NCCR NANO, the Fribourg Center of Nanomaterials FriMat and the University of Fribourg for most generous support.

Received: March 22, 2010

[1] a) M. Steffen, F. Brito, D. Di Vincenzo, M. Farinelli, G. Keefe, M. Ketchen, S. Kumar, F. Milliken, M. B. Rothwell, J. Rozen, R. H. Koch, J. Phys.: Cond. Matt. 2010, 22, 053201/1; b) L. Sanchez-Palencia, M. Lewenstein, Maciej, Nature Phys. 2010, 6, 87; c) D. Mandrus, A. S. Sefat, M. A. McGuire, B. C. Sales, Brian C. Chem. Mater. 2010, 22, 715; d) S. Gariglio, M. Gabay, J.-M. Triscone, Nature Nanotechnol. 2010, 5, 13.

[2] H. Kimura, Ceramic Trans. 2009, 203, 119; P. Hu, X.-H. Zhang, J. C. Han, X.-G. Luo, S.-Y. Du, J. Am. Ceram. Soc. 2010, 93, 345.

[3] a) C. N. R. Rao, J. Mat. Educ. 1991, 13, 419; b) M. Tsuchiya, S. K. R. S. Sankaranarayanan, S. Ramanathan, Progr. Mat. Science 2009, 54, 981

[4] a) Y. Ozturk, I. Avgin, M. Erol, E. Celik, Springer Proc. Phys. 2009, 122, 113; b) S. Bruzaud, Y. Grohens, Int. J. Nanotech. 2008, 5 , 660.

[5] R. W. Schwartz, M. Narayanan, Sol. Proc. Inorg. Mat. 2009, 33.

[6] J. Schwarzkopf, R. Fornari, Progr. Crystal Growth Charact. Mat. 2006, 52, 159.

[7] a) A. Gleizes, S. Sans-Lenain, D. Medus, Acad. Sci. Ser. II 1991, 313, 761; b) A. A. Drozdov, S. I. Troyanov, Polyhedron 1996, 15, 1731; c) S. R. Drake, M. B. Hursthouse, K. M. A. Malik, D. J. Otway, J. Chem. Soc. Dalton Trans. 1993, 2883 ; d) A. Gleizes, A. Drozdov, S. Troyanov, Koord. Khim. 1994, 20, 922; e) J. Auld, A. C. Jones, A. B. Leese, B. Cockayne, P. J. Wright, P. O'Brien, M. Motevalli, J. Mater. Chem. 1993, 3, 1203; f) S. B. Turnipseed, R. M. Barkley, R. E. Sievers, Inorg. Chem. 1991, 30, 1164.

[8] a) D. L. Schulz, B. J. Hinds, D. A. Neumayer, C. L. Stern, T. J. Marks, Chem. Mater. 1993, 5, 1605 ; b) I. M. Watson, M. P. Atwood, S. Haq, Supercond. Sci. Technol. 1994, 7, 672; c) D. A. Neumayer, J. A. Belot, R. L. Feezel, C. Reedy, C. L. Stern, T. J. Marks, L. M. Liable-Sands, A. L. Rheingold, Inorg. Chem. 1998, 37, 5625 .

[9] E. D. Gueneau, K. M. Fromm, H. Goesmann, Chem. Eur. J. 2003, 9, 509.

[10] R. D. Bergougnant, A. Y. Robin, K. M. Fromm, Cryst. Growth \& Design 2005, 5, 1691.

[11] R. D. Bergougnant, A. Y. Robin, K. M. Fromm, Tetrahedron 2007, 63, 10751

[12] K. M. Fromm, E. D. Gueneau, Polyhedron 2004, 23, 1479.

\section{Conclusions}

Multitopic ligands can be easily designed to coordinate selectively two differ-
[13] K. M. Fromm, Angew. Chem. 1997, 109, 24, 2876, Angew. Chem. Int. Ed. Engl. 1997, 36, 2799.

[14] K. M. Fromm, G. Bernardinelli, Z. Anorg. Allg. Chem. 2001, 627, 1626. 
[15] K. M. Fromm, Chem. Comm. 1999, 17, 1659.

[16] K. M. Fromm, E. D. Gueneau, H. Goesmann, Chem. Comm. 2000, 2187.

[17] K. M. Fromm, Chimia 2002, 56, 676

[18] K. M. Fromm, E. D. Gueneau, G. Bernardinelli, H. Goesmann, J. Weber, M.-J. Mayor-López, P. Boulet, H. Chermette, J. Am. Chem. Soc. 2003 $125,3593$.

[19] K. M. Fromm, E. D. Gueneau, A. Y. Robin, W. Maudez, J. Sague, R. Bergougnant, Z. Anorg. Allg. Chem. 2005, 631, 1725.

[20] W. Maudez, T. Vig-Slenters, L. Mirolo, A. Fleury, K. M. Fromm, Main Group Chemistry 2006, 5, 41.

[21] W. Maudez, D. Häussinger, K. M. Fromm, Z. Anorg. Allg. Chem. 2006, 632, 2295.

[22] W. Maudez, M. Meuwly, K. M. Fromm, Chem. Eur. J. 2007, 13, 8302

[23] K. M. Fromm, Dalton Trans. 2006, 43, 5103.

[24] K. M. Fromm, G. Bernardinelli, H. Goesmann, M.-J. Mayor-Lopez, J. Weber, Z. Anorg. Allg. Chem. 2000, 626, 1685.

[25] K. M. Fromm, G. Bernardinelli, H. Goesmann, Polyhedron 2000, 19, 1783.

[26] K. M. Fromm, H. Goesmann, Acta Cryst. Sect. C. $2000,56,10,1179$.

[27] K. M. Fromm, Chem. Eur. J. 2001, 7, 2236.

[28] K. M. Fromm, Cryst. Eng. Comm. 2002, 4, 318.

[29] K. M. Fromm, Chimia 2003, 57, 175.

[30] K. M. Fromm, W. Maudez, Eur. J. Inorg. Chem. 2003, 18, 3440.

[31] W. Maudez, K. M. Fromm, Helv. Chim. Acta 2009, 92, 2349.

[32] K. M. Fromm, Coord. Chem. Rev. 2008, 252, 856.

[33] K. M. Fromm, E. D. Gueneau, J.-P. Rivera, G. Bernardinelli, H. Goesmann, Z. Anorg. Allg. Chem. 2002, 628, 171.

[34] K. M. Fromm, R. D. Bergougnant, Solid State Sciences 2007, 9, 580.

[35] A. Crochet, K. M. Fromm, Z. Anorg. Allg. Chem. 2010, in press.
[36] F. Gschwind, O. Sereda, K. M. Fromm, Inorg. Chem. 2009, 48, 10535.

[37] a) Y. Deng, Q. Lv, S. Wu, S. Zhan, Dalton Trans. 2010, 39, 2497; b) A. F. Hepp, K. Banger, M. H.-C. Jin, J. D. Harris, J. S. McNatt, J. E. Dickman, Sol. Proc. Inorg. Mat. 2009, 157; c) M. A. Malik, P. O’Brien, Chem. Vap. Dep. 2009, 207.

[38] A. Y. Robin, K. M. Fromm, H. Goesmann, G. Bernardinelli, Cryst. Eng. Comm. 2003, 5, 405.

[39] K. M. Fromm, A. Y. Robin, M. Meuwly, H. Goesmann, G. Bernardinelli, Cryst. Eng. Comm. 2004, 6, 336.

[40] K. M. Fromm, E. D. Gueneau, A. Y. Robin, W. Maudez, J. Sague, R. Bergougnant, Z. Anorg. Allg. Chem. 2005, 631, 1725.

[41] T. Dorn, K. M. Fromm, C. Janiak, Aust. J. Chem. 2006, 59, 22.

[42] A. Y. Robin, J. L. Sagué, K. M. Fromm, Cryst. Eng. Comm. 2006, 8, 403

[43] a) A. Y. Robin, J. L. Sagué Doimeadios, A. Néels, T. Vig Slenters, K. M. Fromm, Inorg. Chim. Acta 2007, 360, 212; b) A. Y. Robin, K. M. Fromm, Coord. Chem. Rev. 2006, 250, 2127.

[44] P. S. Brunetto, K. M. Fromm, Chimia 2008, 62, 249.

[45] T. Vig Slenters, I. Hauser-Gerspach, A. U. Daniels, K. M. Fromm, J. Mat. Chem. 2008, 18, 5359.

[46] C. R. Arciola, N. Balaban, L. Baldassarri, K. Fromm, G. M. Hansch, U. Obst, E. Presterl, S. Stefani, J. Verran, L. Visai, Int. J. Artific. Organs 2008, 31, 858 .

[47] K. Belser, T. Vig Slenters, C. Pfumbidzai, G. Upert, L. Mirolo, K. M. Fromm, H. Wennemers, Angew. Chem. Int. Ed. 2009, 48, 3661.

[48] J. L. Sagué Doimeadios, A. Y. Robin, K. M. Fromm, Chem. Commun. 2005, 36, 4548.

[49] J. L. Sague, K. M. Fromm, Crystal Growth \& Design 2006, 6, 1566.

[50] K. M. Fromm, Chimia 2009, 63, 858. 